sudorific, I believe we should often defeat our object by giving it in large quantities.

In order to stimulate the failing hepatic power, and at the same time to introduce some remedy into the intestinal canal which may prevent the putrid decomposition of its contents, I adopted the following formula many years ago, and have regularly employed it since in cases of positively declared enteric fever, as well as in those of doubtful diagnosis: Pulveris ipecacuanhæe compositæe, $1 \frac{1}{2}$ gr. to 10 gr.; hydrargyri cum cretâ, 2 gr.; fiat pulvis; nocte maneque sumenda. Though I advocate the use of mercury in this form, I do not lose sight of the fact that the opium is, on the whole, the much more valuable drug in enteric fever. I give the combination from the earliest to the latest stage of the disease, irrespective of complications, excepting perhaps vomiting. The average time during which it was administered in 156 cases was nineteen days and a half; and mercurialism was induced in a very small proportion, less than 4 per cent., and in these it subsided in the course of a week. The effect of the treatment is to evoke an earlier reappearance of the bile than occurs in cases not so treated. The mortality amongst the 156 cases treated in this manner was 16 , or 10.2 per cent. Constipation, which is as often present as diarrhcea, is best combated by giving a simple enema every second or third day, and sometimes by the use of a small dose of castor oil. When diarrhoea is at all severe, I wash out the lower bowel with warm water containing I per cent. of carbolic acid. A pint or more injected slowly in all cases but those of ulceration of the colon corrects putridity and gives great relief. A soft linseed poultice applied firmly to the abdomen by means of a fiannel roller effectually relieves the local inflammation and prevents the formation of tympanites. For great diurnal variations of temperature and for high degrees $I$ prescribe quinine in doses of not more than ten or fifteen grains.

\section{RUPTURE OF THE POPLITEAL ARTERY; SUCCESSFUL TRANSFUSION. ${ }^{1}$}

\section{BY A. R. ANDERSON, F.R.C.S.}

L. H-, aged fifteen, was admitted into the Nottingham General Hospital on June 30th, 1888, suffering from a swelling above and around the knee. He stated that a month previously he had his right knee crushed between two colliery trams. Directly afterwards the parts about the knee became painful and much swollen, and he was unable to walk or to move the limb. He was attended at home for four weeks, and then came to the hospital. On admission, the lower third of the thigh was much swollen, the skin tense and slightly cedematous, and on the inner side was a circumscribed red patch where the integument was distinctly thinner, as though an abscess were pointing there. The part was distinctly hot. There was slight cedema of the leo and foot. There was an evident fluctuation over the inflamed spot in the thigh. Pain was great and movement of the knee impossible, although it was evident that the joint itself was not implicated. He lay with the limb flexed and on its outer side. For two days the boy was treated with hot fomentations, and then an incision was made on the inner side over the red patch, and some turbid serum and blood-clot escaped, but no actual pus. A counteropening was made on the other side and a drainage-tube inserted; this was on July 2nd. The wounds were dressed antiseptically daily, and some further broken-up blood-clot came away, but nothing of note occurred. On July 10 th, without any warning, a very violent hæmorrhage took place. The bed was soaked with arterial blood; the boy blanched and gasping for breath. Jactitation was well marked. There was a death-like pallor; skin cold and sweating. He was almost pulseless-indeed, it was only in the larger vessels that it could be felt ; it could not be made out in the radials. The femoral was instantly compressed, and a Petit's tourniquet applied ; ether was injected under the skin, and brandy given, but with scarcely any effect. The boy appeared to be sinking, and was to all appearance moribund. The opposite femoral and both brachials were

${ }^{1}$ A short abstract of this paper was printed in our impression of April 13th. -ED. I. temporarily compressed, in order the better to supply the heart and brain with what blood remained in his body. He showed no signs of rallying, however, under this treatment, the heart's action being tumultuous, irregular, and intermittent, and it became apparent to all that unless something was done promptly he would soon be beyond the reach of surgical aid. Transfusion was the only method of treatment which held out any prospect of success, and, as there was no proper apparatus at hand for the purpose, I operated in this way : A small cannula from a pocket trocar was attached to an indiarubber tube, and to the other end of the tube a glass funnel. The solution used was two grains of chloride of sodium to the ounce of warm water (temperature $100^{\circ}$ ), and eighteen ounces of this was allowed to flow into the median basilic vein, with marvellous and immediate effect. The action of the heart became strnnger, quieter, and more regular, the jactitation ceased, and the pulse, which had previously been imperceptible at the wrist, became restored. Within two hours he sat up in bed and asked for his tea. The tourniquet was kept loosely applied over the femoral, and the part carefully watched during the night for further bleeding. None occurred, and the next morning he had rallied so far as to make a deliberate operation practicable. Mr. Wright, senior surgeon to the hospital, enlarged the wound on the inner side of the thigh, exposing a cavity reaching behind the femur, and containing débris of blood-clot \&c., and at the bottom lay the popliteal artery, which was found partially ruptured, and from this the hæemorrhage had evidently proceeded. A ligature was placed on both sides of the wounded spot, the cavity well cleansed out, a drainage-tube inserted, and the wound closed. There was but little blood lost at the operation; the patient, however, again passed into an alarming state of pallor and pulselessness at the wrist, preceded by irregular, tumultuous cardiac beating, and restlessness. Seemg that death was again impending, with the cunsent of those present $I$ introduced twelve ounces of the same solution into the median basilic vein of the other arm, with marked benefit as before. On July 13th, two days later, the wound was dressed and he had rallied fairly well. From this time improvement took place daily. At the end of a week he was put on a course of iron. No further hremorrhage occurred, the wound healed without interruption, and he was discharged cured on Sept. 1st.

Although rupture of the popliteal artery from violence without external wound is an uncommon accident, still this vessel is more commonly so injured than, I believe, any other in the body, the axillary ranking next in this respect. There are various anatomical conditions which doubtless account for this, and which need not be entered into here but I would remark that, with the knee fully extended, the vessel is in a state of tension, and is perhaps specially tense at those points where its branches are given off. In speaking of the rupture of arteries generally from violence, writers have from time to time noticed the fact that the lesion occurs, as a rule, close to the giving off of some branch. In this case the rupture occurred just at the origin of the superior internal articular artery, which had itself given way at a spot about an inch from its origin, and was found lying torn at the bottom of the wound. The symptoms of this accident are, of course, well known. In complete rupture the nature of the case would be clearly indicated by the sudden and great swelling of the popliteal space, the absence (as a rule) of pulsation in this swelling, the coldness of the limb, and cornplete cessation of pulsation in the vessels below. In partial rupture, more commonly than not the swelling in the ham pulsates; some pulsation can also be felt in the tibials, and there is but little lowering of temperature in the limb.

Now, in considering the symptoms observed in this case, the interesting question arises, Conld rupture of the popliteal artery, whether partial or complete, have been diagnosed at the time of the patient's admission into hospital? He arrived there a month after the injury, and one was confronted by the following signs: (1) Swelling of the whole limb round the lower third of the femur, most marked on the front and inner side of the thigh; (2) redness and thinning of the skin in that situation, with a distinct sense of fluctuation; (3) absence of pulsation in the swelling; (4) practically no interference with the circulation in the leg and foot, which were warm and natural in appearance, with the exception of a slight oedema, which might have been easily accounted for by the inflammatory centre in the thigh; and (5) there was pyrexia. Considering the age of 
the youth, the situation and character of the swelling, and the nistory of the case, the opinion was formed that it was one of a limited acute periostitis with localised abscess, such as is known sometimes to occur. This turned ont to be incorrect; but, considering the vague and misleading signs that presented themselves on examination, it is doubtful whether a correct diagnosis could have been made at this stage. When the incision was made into the swelling, shortly after the patient's admission, and it was found to contain nothing but turbid serum and some dark blood-clot, suspicions were naturally aroused, but nothing definite could be arrived at beyond the fact that there had been an extravasation of blood into the limb, Jying chiefly behind the femur, and that what little blood towed was dark and venous in character. And it may here be remarked, in passing, that, in cases presenting clear signs of lesion of a bloodvessel in the popliteal space following injury, it is almost certain to be the artery which has given way, and not the vein. Whilst injury to the artery without implication of the vein is the rule, especially in incomplete rupture, no record of any case in which the vein alone suffered can be found in the English medical journals for the last thirty years-an immunity which may perhaps be explained by reference to its anatomy.

With respect to the treatment of this accident, the most satisfactory method appears to be that of cutting down on and tying the ends of the ruptured vessel, in both the incomplete form and also when complete, if the case be seen before gangrene has become in evitable. It is true that distinguished surgeons have occasionally, but I think very rarely, failed to find the ends of the vessel amid the mass of blood and débris. ${ }^{2}$ But in favour of this operation it may be said--(1) that it places the patient in the safest condition possible as far as the risk of any recurrence of the hænorrhage is concerned; (2) that by early clearing out of the masses of clot \&c. from the popliteal space a potent factor in the production of gangrene is removed-namely, the pressure on the collateral circulation; and (3) that, if gangrene should unfortunately ensue, amputation can easily be performed, with a scarcely diminished prospect of success. In partial rupture ligature of the femoral has been advocated. But the objection to the operation appears to lie in this, that if with an enfeebled circulation in the limb, such as must be present with a partially ruptured popliteal artery, the femoral is ligatured, the risk of gangrene would surely be as great or oreater than if the vessel were cut down on and tied. And, as a matter of fact, out of eight recorded cases in which this operation was performed for partial rupture, gangrene of the limb ensued in six. And, again, if after ligature of the femoral the collateral circulation became sufficiently established to ensure the vitality of the limb, there would be every probability of further leakage from the injured vessel. In conclusion, I would draw attention to the simple method by which the intra-venous saline solution was injected, and to the very gratifying result obtained therefrom: and also to the fact that on leaving the hospital the boy seemed none the worse for the substitution of a pint and a half of salt and water for the arterial blood lost. Nottingham.

\section{ABDOMINAL ANEURYSM TREATED BY TUENELL'S METHOD AND IODIDE OF POTASSIUM; RECOVERY.}

\section{By JOHN ROSS, M.B.}

IN the beginning of June, 1888, I saw Mrs. S-, aged twenty-one. She complained of a lump, pain, and throbbing in the epigastrium. The pain was not acute, but dragging, and of an oppressive nature. She did not think much of these symptoms, and was doing her usual household duties in the ordinary way. Her health was otherwise good. The above symptoms had been gradually coming on for the previous six months; they began shortly after or about the time she was nursing her husband, a big, heavy man, who had been suffering from pleurisy and was laid up for two months. During this period she was the sole attendant, and had to move him in bed every time he required it. She was a fairly built, small woman, well nourished, but spare and wiry On examination I found a distinct elastic pulsating tumour in the middle line of the epigastrium, the upper part slightly overlapped by the ensiform process. The tumour was about three inches in length, and of the circumference of an ordinary-sized orange. There was no difficulty in getting the hand over and partly round the tumour, as the abdominal walls were thin and flaccid. This was especially easy after the first two days of treatment. When the hand was so placed, distinct pulsatile expansion was experienced. On auscultation a systolic murmur was audible over the tumour. There was slight pain on pressure, especially at a spot on the left side of the tumour. The previous history was good; she had never had any illness that confined her to bed for a day that she could remember. There were no signs or history of syphilis.

The management of the case presented a difficulty. Her husband (a mason) was away working in Natal, she had no relatives in the town, and there was only one person, a woman, whom she knew at all intimately. She did not consider that there was much the matter with herself, and thought that a little medicine would be sufficient to make her well. She was naturally sprightly and industrious. Under these circumstances I had some misgivings about telling her suddenly of the seriousness of her case, but told her that she would have to keep in bed for some weeks. She was much surprised at the treatment proposed, and seemed to think I was treating the matter too seriously. It was therefore difficult to persuade her to submit to treatment, and when she yielded it was in a doubting, half-hearted manner. I mention all this because I think that under better conditions the treatment would have proved beneficial in a shorter period, and to show that even in adverse circumstances there is good reason to persevere. The treatment was absolute rest ; Tufnell's diet ; iodide of potassium (fifteen grains) and tincture of aconite (five minims) thrice daily; and the bowels to be attended to.

A week after the treatment was begun the pain was much relieved, and the tumour was decidedly firmer. A fortnight later, on calling unexpectedly, I found the patient sitting up in bed with her child beside her; she had no doubt been lifting it. I found no further improvement in the symptoms. Her friend, who was in at the time, then said there was no use deceiving me, and that the treatment was not being carried out as directed, as far as the absolute rest was concerned. I then determined to tell the patient the very serious nature of her illness, and told her that if she was not very careful she might die at any moment. After this I have no doubt that the treatment was carried out fairly well. A week afterwards the tumour was quite hard, and the expansile pulsation had disappeared, as had also the systolic murmur; but there remained a pulsation like that of the radial pulse down the median line of the tumour, as well as a pulsating spot on the left side of the tumour. This was the state of things when I left the colony two months afterwards.

On Dec. 30th Dr. Savage, whom I left in charge of the case, wrote: "A fortnight back I saw Mrs. S_ and found everything normal; no swelling or tumour, and no pulsation. I did not vary the treatment, except once when the pulse got irregular, and I then gave her a little digitalis. She had been up for six weeks. "She does not exert herself." A fortnight later he wrote: "I cannot tell you how Mrs. Sis, as she has gone to East London," from which I concluded that she was still well.

On April 25th, 1889, I received the following concerning the case of this patient from Dr. Savage: "Mrs. S- - has gone to Natal. I got her to see Dr. Mackenzie, of Durban, who thinks she has entirely recovered." This is dated March 31st, 1889. Natal is 350 miles from King William's Town, and the sea voyage to it is a very rough one, and entails the crossing of two of the worst bars on the South African coast. I think that this test by an exceptionally rough passage is about as severe a legitimate test as any case of the nature could have been put to. I am sure that those who know anything of the voyage, even under the most favourable circumstances, will agree with me.

I think this case well illustrates what the above treatment can do, if only sufficient patience be exercised. The patient was in bed from the beginning of June until the end of October (five months).

King William's Town, Cape Colony. 